\title{
Centro de Referência Virtual: o Uso de REA na Formação Continuada de Professores
}

\author{
Elizabeth Soares Ramalho Bastos', Maria Cristina Pfeiffer Fernandes*2 \\ ${ }^{1}$ Diretoria de Extensão/Fundação CECIERJ. Rio de Janeiro - Brasil. bethbastos@cecierj.edu.br \\ 2 Diretoria de Extensão/Fundação CECIERJ. Rio de Janeiro - Brasil. pfeiffer@cecierj.edu.br
}

\section{Resumo}

A Fundação Centro de Ciências e Educação Superior a Distância (CECIERJ) e a Secretaria de Estado de Educação (SEEDUC/RJ) do Rio de Janeiro oferecem, desde 2011, formação continuada para professores do ensino fundamental e médio, com 15 mil professores já capacitados até junho de 2014. Por meio de cursos de aperfeiçoamento atrelados a uma especialização nas disciplinas Matemática, Língua Portuguesa, História, Biologia e Ciências, os professores da rede estadual são capacitados para usarem em sala de aula o currículo mínimo e dinâmicas do reforço escolar em Língua Portuguesa e Matemática. Visando disponibilizar o material do professor, as dinâmicas do reforço escolar e os planos de trabalho elaborados pelos cursistas, foi criado o repositório Centro de Referência Virtual (CRV), integrado ao Portal TECA (http://teca.cecierj.edu.br/). Experiências de sucesso desses professores, metodologias inovadoras, além de outros temas relacionados à educação básica são divulgados na nova versão eletrônica da revista Educação Pública (http://educacaopublica.cederj.edu.br), também integrada ao CRV.

Palavras-chave: currículo mínimo; educação básica; REA. 


\title{
Virtual Reference Center: the Use of OER in Continuing Education of Teachers
}

\begin{abstract}
The Fundação Centro de Ciências e Educação Superior a Distância - CECIERJ and the Secretaria de Estado de Educação - SEEDUC/RJ of Rio de Janeiro offer, since 2011 , continuing education of teachers of elementary and secondary education, with 15 thousand teachers trained until June 2014. Through improvement courses linked to a specialization in subjects as Mathematics, Portuguese, History, Biology, and Science, state school teachers are trained to use the minimum curriculum and school reinforcement dynamics in portuguese and mathematics in the classroom. In order to make the professor's material, the dynamics of school reinforcement, and course participants' workplans available, the repository Centro de Referência Virtual - CRV was crated and integrated with the Portal TECA (http://teca.cecierj.edu.br). Successful experiences of these teachers and innovative methodologies, as wellother topics related to basic education, are disclosed in the new electronic version of the magazine Educação Pública (http://educacaopublica.cederj.edu.br) and integrated with the CRV.
\end{abstract}

Keywords: basic education; minimum curriculum; OER. 


\section{Introdução}

A Fundação Centro de Ciências e Educação Superior a Distância do Estado do Rio de Janeiro (CECIERJ) tem como uma de suas atribuições "Formação continuada de professores do ensino fundamental, médio e superior" (art. $2^{\circ}$ da Lei Complementar no 103, de 18 de março de 2002). Em 2011, por meio da Diretoria de Extensão, a Fundação firmou uma parceria com a Secretaria de Estado de Educação (SEEDUC) do Rio de Janeiro, para reformular o currículo mínimo das disciplinas Matemática, Língua Portuguesa, História, Biologia e Ciências, trabalhadas em sala de aula pelos professores da rede estadual. Além disso, essa parceria também gerou mais dois projetos: Reforço Escolar e Nova EJA (NEJA), uma nova política de educação de jovens e adultos do Estado do Rio de Janeiro.

Por meio do Programa de Formação Continuada (http://projetoseeduc.cecierj.edu.br/principal/formacao-continuada.php) implementado no AVA Moodle, foram elaborados cursos em Matemática, Língua Portuguesa, História, Biologia e Ciências, visando preparar os professores para o uso do currículo mínimo no cotidiano da sala de aula. Neste curso de aperfeiçoamento, diversas ações são realizadas, dentre as quais a elaboração, pelos cursistas, de planos de trabalho para a aplicação do currículo mínimo em sala de aula, que busquem, cada vez mais, a autonomia autoral dos professores.

Até junho de 2014, 15 mil professores já participaram desta formação. A fase de aperfeiçoamento on-line pode se desdobrar em especialização, realizada nas seis universidades públicas parceiras do Consórcio Centro de Ensino a Distância do Estado do Rio de Janeiro (CEDERJ) da Fundação CECIERJ (UFRJ, UFF, UNIRIO, UFRRJ, UERJ, UENF). O objetivo principal deste projeto da SEEDUC/RJ e da Fundação CECIERJ é conduzir os alunos da rede estadual ao desenvolvimento de habilidades apontadas como críticas e, como fruto natural desse desenvolvimento, alcançar a melhoria da aprendizagem e desempenho nas avaliações de larga escala.

Para intensificar ações que contribuam para uma formação permanente de professores, a Diretoria de Extensão da Fundação CECIERJ elaborou o projeto Centro de Referência Virtual (CRV): compartilhando experiências de sucesso na formação continuada de professores, um projeto de educação e divulgação, no âmbito do ensino fundamental e ensino médio, destinado aos professores das escolas 
da rede pública do Estado do Rio de Janeiro, englobando duas frentes de trabalho: 1) a primeira está associada à criação do Centro de Referência Virtual (CRV), um espaço de compartilhamento de recursos educacionais abertos (REA) integrados ao Portal TECA (http://teca.cecierj.edu.br), um repositório de objetos educacionais da Fundação CECIERJ; 2) a segunda frente de trabalho está associada à implementação de uma nova versão da revista Educação Pública (http://educacaopublica.cederj.edu.br), da Fundação CECIERJ, como um espaço de divulgação da educação básica. Essa nova versão da revista também está integrada ao CRV por meio do Portal TECA. O artigo está dividido em: introdução, fundamentação teórica, metodologia, discussão dos resultados já alcançados, considerações finais e trabalhos futuros.

\section{Fundamentação teórica}

Os conhecimentos são evolutivos e progressivos e isto exige que, após seus estudos universitários iniciais, profissionais de todas as áreas busquem um aperfeiçoamento constante em sua formação, a partir de diferentes meios (Tardif, 2002). As inovações tecnológicas podem contribuir de modo decisivo para transformar a escola em um lugar de exploração de culturas, de realização de projetos educacionais de qualidade, de investigação e debate.

Essas são características da sociedade pós-moderna que vemm colocando novas exigências ao saber, ao saber-fazer e, sobretudo, ao saber como fazer profissionais. E isso ocorre principalmente na área educacional, exigindo que o professor "deve conhecer sua matéria, sua disciplina e seu programa, além de possuir certos conhecimentos relativos às ciências da educação e à pedagogia e desenvolver um saber prático baseado em sua experiência cotidiana com os alunos" (Tardif, 2002). Segundo Imbérmon (2001), os principais eixos de atuação na formação permanente do professor incluem a reflexão prático-teórica sobre a própria experiência profissional mediante a análise, a compreensão, a interpretação e a intervenção sobre a realidade.

A capacidade de um professor gerar conhecimento pedagógico por meio da prática educativa permite a troca de experiências entre iguais para tornar possível a atualização em todos os campos de intervenção educativa e aumentar a comunicação entre os docentes. O desenvolvimento profissional da instituição educativa mediante o 
trabalho conjunto para transformar essa prática deve possibilitar a passagem da experiência de inovação (isolada e individual) à inovação institucional.

A educação a distância pode vir a ser uma forma viável e democrática de ampliar a oferta educacional para todas as pessoas. A abolição das restrições de espaço e tempo para a realização de ensino de qualidade para todos esbarra, no entanto, na democratização do acesso à tecnologia e na formação de professores e profissionais para a viabilização de projetos educacionais significativos (Kenski, 2011).

Essa conjunção de fatores deu início a um processo nas diversas instituições acadêmicas ao redor do mundo no sentido de disponibilizar conteúdos abertos (open content), desenvolvidos de forma colaborativa, assim como se faz no desenvolvimento de software livre. Com o amadurecimento dessa ideia, o escopo do movimento de conteúdos abertos cresceu para abranger os demais recursos educacionais digitais utilizados para ajudar no desenvolvimento e disponibilização destes conteúdos, surgindo assim os recursos educacionais abertos, ou simplesmente REA, que são mais conhecidos por sua sigla em inglês OER (open educational resources) (Dutra, 2007).

Os REA são definidos como "estratégias para aumentar o acesso a materiais educacionais eletrônicos" (Roll, 2005 apud Santos, 2006), por meio do uso da tecnologia (internet, wikis, ambientes virtuais de aprendizagem - AVAs) e abrangem os conteúdos de aprendizagem, ou seja, cursos, módulos de conteúdo, objetos de aprendizagem entre outros. Por meio dos REA, é possível disponibilizar, gratuitamente, conteúdos educacionais em websites para uso didático, podendo incluir texto, som e imagem e possibilitando seu reuso em diversos contextos educacionais (Santos, 2006). Além disso, esses materiais poderão ser usados e reutilizados de diversas formas: por meio de modificações de estilo e conteúdo, acréscimo de informações, traduções e versões, bem como poderão ser utilizados de forma institucional ou coletiva por indivíduos interessados em um determinado conteúdo e que desejem criar uma "comunidade de aprendizagem" sobre tal tema de interesse (Santos, 2006).

Os REA incluem também ferramentas para apoiar o desenvolvimento, uso, reuso, busca e organização de conteúdos, bem como sistemas de gerenciamento de aprendizagem e ferramentas de autoria. E, por último, os REA contemplam os chamados recursos de implementação que abrangem licenças para a disseminação de materiais abertos, bem como recursos de localização de conteúdos (Johnstone, 2005 
apud Dutra, 2007). Segundo Knight (2006, apud Santos, 2006), o que garante a qualidade de um REA é incentivar a reutilização de materiais educacionais, possibilitando a formação de parcerias para a criação e disponibilização dos conteúdos abertos. Segundo Litto (2006, apud Santos, 2006), "com OER (open educational resources) disponibilizando gratuitamente quase todo o conhecimento moderno essencial, em forma textual, visual e sonora, e, sob demanda, a aprendizagem não formal, na hora certa, tenderá a ficar maior que o antigo sistema formal e convencional".

Duas das maiores iniciativas internacionais em recursos educacionais abertos são o MIT OpenCourseWare (Universidade de Massachusetts, EUA http://ocw.mit.edu/index.html) e a Open Content Initiative (OCI - The Open University - Reino Unido - http://oci.open.ac.uk), conhecido como OpenLearn. Existem outras iniciativas na China, Japão, França e Vietnã (Santos \& Okada, 2006 apud Santos, 2006).

\section{Metodologia}

Nesta seção, são descritos os procedimentos metodológicos adotados para a implementação do projeto descrito neste trabalho.

\subsection{Parceria SEEDUC/RJ - Fundação CECIERJ}

Em 2011, por meio de uma parceria entre a Fundação Centro de Ciências e Educação Superior a Distância (CECIERJ) e a Secretaria de Estado de Educação (SEEDUC/RJ) do Rio de Janeiro, iniciou-se a reformulação do Currículo Mínimo Regular a ser adotado nas escolas estaduais referente ao $9^{\circ}$ ano do ensino fundamental e $1^{a}$, $2^{a}$ e $3^{a}$ séries do ensino médio. Após a efetivação do currículo mínimo e visando preparar os professores da rede estadual quanto à aplicação deste currículo na sala de aula, foi elaborado por 36 especialistas o Programa de Formação Continuada nas disciplinas Matemática, Língua Portuguesa, História, Biologia e Ciências. Até junho de 2014, já foram capacitados 15 mil professores, e não é apenas uma capacitação, mas sim um curso de aperfeiçoamento com a elaboração, pelos cursistas, de planos de 
trabalho que promovam cada vez mais a capacidade do professor de ser autor de seu próprio material. Esse curso pode se desdobrar em especialização oferecida pelas seis universidades públicas do Consórcio Centro de Educação Superior a Distância do Rio de Janeiro (CEDERJ) (UFRJ, UFF, UniRio, UFRRJ, UERJ e UENF).

O Programa de Formação Continuada tem carga horária de 160 horas de aperfeiçoamento. Além dessas, são oferecidas disciplinas completando outras 200 horas, para caracterizar um curso de especialização com duração de 11 meses. Prevêse que, durante sua realização, o professor deva dedicar quatro horas semanais às atividades do curso, além dos encontros presenciais tendo a duração de três horas cada um.

Os especialistas que trabalharam no Programa de Formação Continuada foram também os responsáveis pelo desenvolvimento dos materiais didáticos para o projeto Nova EJA (NEJA) (http://projetoseeduc.cecierj.edu.br/principal/nova-eja.php), uma nova política de educação de jovens e adultos do Estado do Rio de Janeiro com metodologia e currículo específicos, material didático próprio, recursos multimídia, aulas dinâmicas e metodologia para ser trabalhada com alunos em defasagem idade/série.

O projeto Reforço Escolar (http://projetoseeduc.cecierj.edu.br/principal/reforcoescolar.php), outro projeto desenvolvido numa parceria com a SEEDUC, visa priorizar ações qualitativas na educação, tendo como foco as necessidades de letramento em leitura e escritas, além de letramento matemático, para os alunos do 90 ano do ensino fundamental e $1^{a}, 2^{a}$ e $3^{a}$ séries do ensino médio regular. O objetivo principal do projeto é conduzir os alunos da rede estadual ao desenvolvimento de habilidades apontadas como críticas e, como fruto natural desse desenvolvimento, alcançar a melhoria da aprendizagem e desempenho nas avaliações de larga escala. Trabalharam 16 especialistas em Língua Portuguesa e Matemática para o desenvolvimento dos materiais utilizados pelos professores e alunos participantes do projeto Reforço Escolar em que são disponibilizados objetos educacionais associados aos planos de trabalho dos professores cursistas que participam dos cursos de formação continuada e aperfeiçoamento on-line.

Para a orientação dos planos de trabalho dos professores da rede estadual que cursaram a fase de aperfeiçoamento on-line, por meio do AVA Moodle, trabalharam 56 
especialistas e cerca de 600 tutores (presenciais e a distância) atuando nos projetos de Reforço Escolar, Nova EJA (NEJA) e Formação Continuada para currículo mínimo regular. Houve também a participação de uma equipe administrativa de apoio aos projetos de formação curricular.

\subsection{Sobre a implementação do projeto FAPERJ}

Em maio de 2013, foi submetido um projeto à Fundação Carlos Chagas Filho de Amparo à Pesquisa do Estado do Rio de Janeiro - FAPERJ, por meio do Edital no 19/2013 "Programa Apoio à Instituição Estadual de Educação Superior a Distância e Divulgação científica - CECIERJ/CEDERJ - 2013", intitulado "Centro de Referência Virtual: compartilhando experiências de sucesso na formação continuada de professores", solicitando fomento, que foi liberado em junho de 2013sob o número de processo E-26/111.124/2013.

Sendo um projeto de educação e divulgação, no âmbito da educação básica (ensino fundamental e ensino médio), destinado aos professores das escolas da rede pública do estado do Rio de Janeiro, o projeto englobou duas frentes de trabalho: 1) criação do Centro de Referência Virtual (CRV) (http://teca.cecierj.edu.br), um espaço de compartilhamento de recursos educacionais abertos (REA);2) a segunda frente está associada à implementação de uma nova versão da revista Educação Pública (http://educacaopublica.cederj.edu.br) da Fundação CECIERJ que está integrada ao CRV por meio do Portal TECA e corresponde a um espaço de divulgação de temas associados à educação básica, destacando-se principalmente as experiências de sucesso dos professores da rede estadual no que diz respeito à aplicação do currículo mínimo na sala de aula.

Para a implementação do projeto, foram adquiridos novos equipamentos e providenciada à contratação da equipe de desenvolvimento locada na Diretoria de Extensão e formada por: web designers, programadores, diagramadores e professora com experiência em cadastramento de objetos educacionais. Após a assinatura do termo de outorga e a liberação da verba pela FAPERJ, foi dado início à execução do projeto conforme descrito a seguir. 


\subsubsection{Implementação do Centro de Referência Virtual - CRV}

A principal motivação da criação do CRV foi criar um repositório de recursos educacionais abertos (REA) que correspondem aos planos de trabalho, planos de ação e material didático do aluno e professor produzidos por meio dos projetos da parceria com a SEEDUC: Programa de Formação Continuada, Reforço Escolar e Nova EJA (NEJA). O CRV está integrado ao Portal TECA (http://teca.cecierj.edu.br), um repositório de objetos educacionais da Fundação CECIERJ que foi adaptado pela equipe de programadores contratada para agregar o CRV. Ao mesmo tempo, os coordenadores das diversas áreas do conhecimento envolvidos nos três projetos fizeram uma seleção dos materiais produzidos, tais como planos de trabalho, roteiros de atividades e orientações pedagógicas, produzidos durante o Programa de Formação Continuada (ensino fundamental, ensino médio regular); planos de ação, material didático do aluno e do professor produzidos durante o projeto Nova EJA (NEJA) e dinâmicas de reforço escolar para Língua Portuguesa e Matemática. O encaminhamento desses documentos foi feito para a professora responsável pelo cadastramento de todo esse material no CRV.

\subsubsection{Implementação da nova versão da revista Educação Pública}

Visando à construção de nova versão da revista Educação Pública (educacao.publica.cederj.edu.br), foi adotada uma arquitetura de informação usando o Wordpress. Foram realizadas várias reuniões com a equipe responsável pela revista para se definir a configuração da nova versão, por meio da combinação dos campos já existentes com os novos campos introduzidos em função da integração com o CRV. A Figura 1 mostra a interface da versão antiga da revista: 


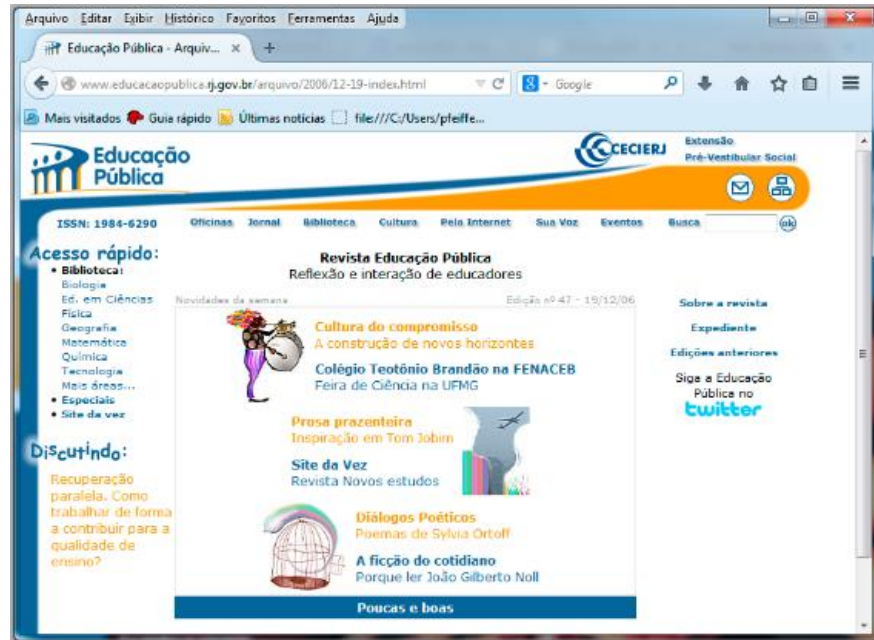

Figura 1. Versão antiga em HTML da revista Educação Pública.

Fonte: http://www.educacaopublica.rj.gov.br/arquivo/2006/12-19-index.html

Em seguida realizou-se a migração do material antigo da revista em HTML (Figura 1) para a nova versão em Wordpress (Figura 2) acompanhada de uma triagem rigorosa do material migrado por um conselho editorial de professores doutores, que também são os coordenadores das cinco áreas do conhecimento da Diretoria de Extensão (Ciências da Natureza, Ciências Humanas, Linguagens e Códigos, Matemática, Prática Docente e Tecnologia Educacional).

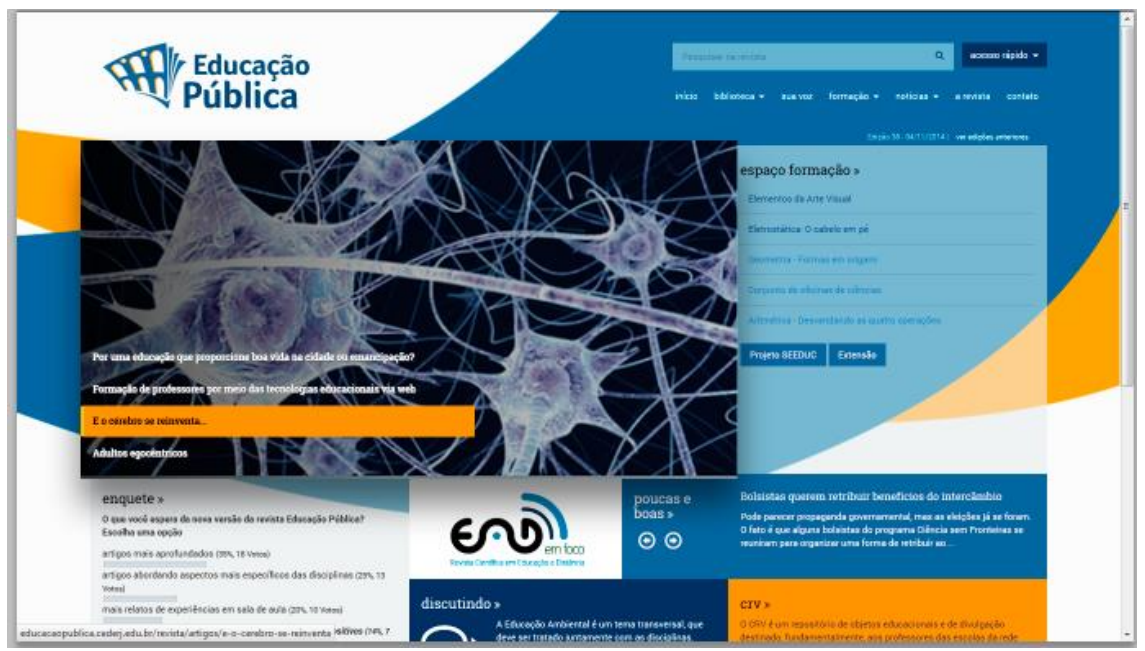

Figura 2. Nova interface da revista Educação Pública. Fonte: http://educacaopublica.cederj.edu.br

Os coordenadores do Programa de Formação Continuada das disciplinas de Língua Portuguesa e Matemática também selecionaram experiências de sucesso referentes à aplicação do currículo mínimo em sala de aula, relatadas por professores da rede estadual durante os cursos de Formação Continuada. Esses relatos de sucesso 
estarão no espaço denominado "Sua Voz" da revista que incluirá também "Ideias para a sala de aula", onde serão inseridas propostas metodológicas inovadoras, assuntos ligados à gestão escolar, um fórum "Discutindo" que favorecerá, de forma assíncrona, troca de ideias sobre temas atuais ligados à educação básica e a "Enquete", um formulário para realização de pesquisas com os professores.

\subsubsection{Oficinas pedagógicas para divulgação do projeto}

Após a implementação dessas duas frentes de trabalho, foram planejados encontros e oficinas em diferentes regiões do Estado do Rio de Janeiro, para a divulgação, entre os professores da rede estadual de ensino, do repositório CRV e da nova versão da revista Educação Pública. Nesses encontros, pretende-se ofertar cursos sobre o uso de novas tecnologias como recursos pedagógicos, principalmente as utilizadas nos planos de trabalho e que foram publicadas no sítio CRV.

\section{Resultados e discussão}

Já foram cadastrados até novembro de 2014 cerca de 2.899 documentos no CRV (teca.cecierj.edu.br) (Figura 3) para consulta gratuita. Os documentos estão associados aos $1^{\circ}, 2^{\circ}, 3^{\circ}$ e $4^{\circ}$ bimestres do $9^{\circ}$ ano do ensino fundamental e aos $1^{\circ}$, $2^{\circ}, 3^{\circ}$ e $4^{\circ}$ bimestres da $1^{a}, 2^{a}$ e $3^{a}$ séries do ensino médio, e aos módulos 1,2 e 3 do projeto Nova EJA (NEJA). Associados à disciplina de Língua Portuguesa, já estão disponíveis para consulta 1.158 roteiros de atividades (planos de trabalho), elaborados pelos professores cursistas do Programa de Formação Continuada, 171 dinâmicas e 64 links para objetos de aprendizagem (vídeos, imagens, etc.) ligados ao projeto Reforço Escolar. Em relação à disciplina de Matemática, já foram cadastrados 813 planos de trabalho elaborados pelos professores cursistas do Programa de Formação Continuada e 243 dinâmicas de reforço escolar. Nessa disciplina também já estão disponibilizados para consulta gratuita 297 planos de ação do projeto Nova EJA (NEJA). Relativo à disciplina Ciências Biológicas, foram cadastrados 20 planos de ação associados ao terceiro bimestre da $1^{a}$ série do ensino médio. 


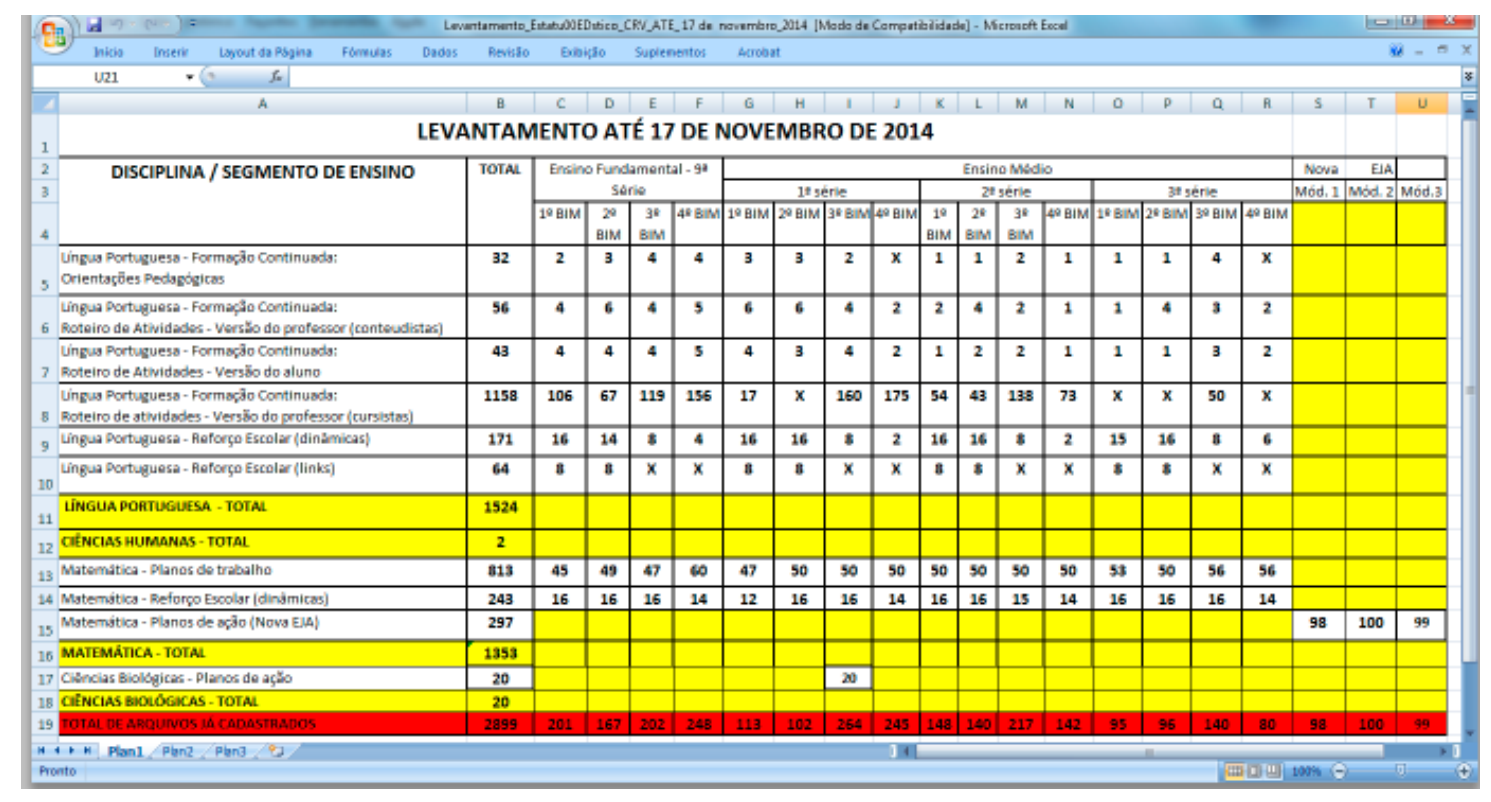

Figura 3. Mapeamento dos REA já cadastrados no CRV até novembro/2014. Fonte: http://teca.cecierj.edu.br

Os impactos gerais promovidos pelo projeto são a consolidação de um espaço repositório virtual - o sítio Centro de Referência Virtual (CRV) no âmbito do ensino fundamental, ensino médio e EJA, integrado ao Portal TECA (Figura 4) e a editoração de uma nova versão da revista de divulgação da educação pública (REP) (Figura 2).

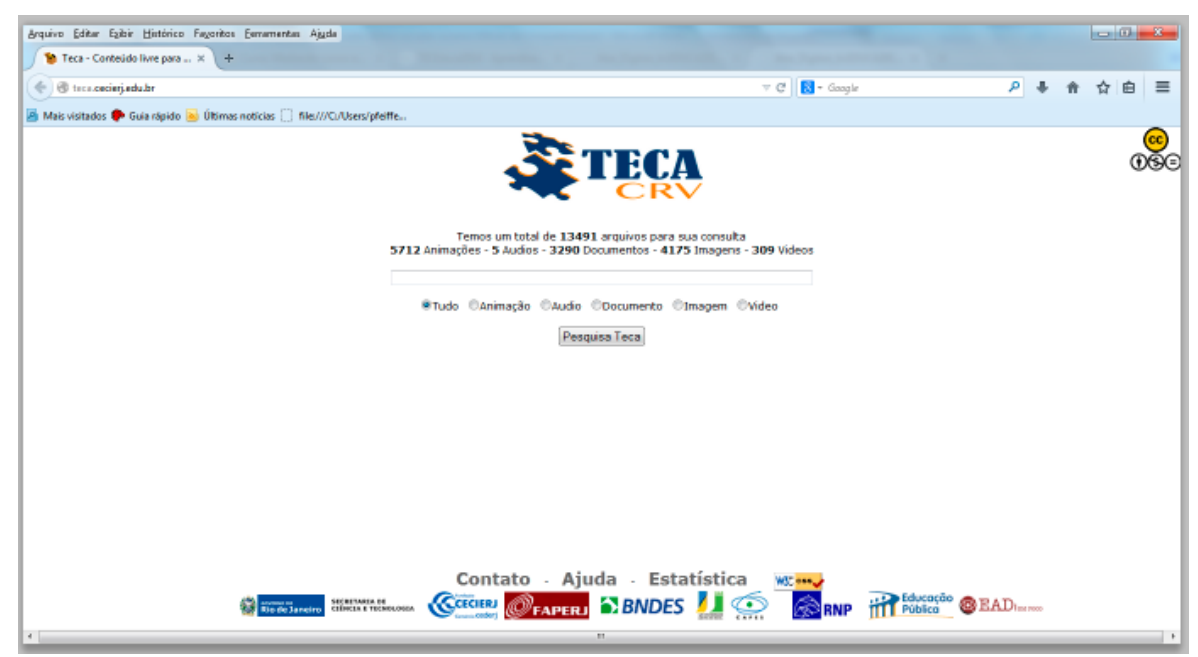

Figura 4. Sítio TECA/CRV.

Fonte: http://teca.cecierj.edu.br

Como impactos específicos vale destacar que o acesso ao sítio CRV implicará numa otimização da aplicação do currículo mínimo em sala de aula pelos professores 
da rede estadual de ensino, que poderão consultar e/ou utilizar o material disponibilizado em seus planejamentos, como referência para o desenvolvimento de habilidades, os descritores que compõem o Sistema de Avaliação da Educação Básica (Saeb), o Sistema de Avaliação da Educação do Estado do Rio de Janeiro (SAERJ) e o Índice de Desenvolvimento da Educação Básica (Ideb). Ou seja, por meio do CRV, os professores da rede estadual de ensino poderão obter um apoio à sua prática docente. Vale ressaltar também que, a partir da implementação da nova versão da revista Educação Pública (Figura 2), será possível o desenvolvimento de uma nova postura dentro da prática do magistério por meio da valorização das experiências bemsucedidas dos professores da rede estadual de ensino no que diz respeito ao uso do currículo mínimo em sala de aula.

Durante a avaliação dos eventos e oficinas previstos para o primeiro e segundo semestres de 2015 com os professores da rede estadual de ensino, pretende-se medir, por meio de relatórios de acompanhamento, os resultados do uso do sítio CRV das consultas realizadas pelos professores à nova versão eletrônica da revista Educação Pública e de que forma esses recursos contribuirão para uma inovação tecnológica e metodológica em ambiente escolar da rede pública de ensino.

\section{Considerações finais e trabalhos futuros}

Já ganham visibilidade os resultados do Programa de Formação Continuada, conforme descrito a seguir. O Índice de Desenvolvimento da Educação Básica (Ideb) é um indicador educacional brasileiro que relaciona informações de rendimento escolar (aprovação) e desempenho (proficiências) em exames padronizados como a Prova Brasil e o Sistema de Avaliação da Educação Básica (Saeb). Uma das principais referências para políticas educacionais na educação básica, o Ideb é divulgado a cada dois anos. O indicador mede a qualidade do aprendizado e da infraestrutura das cerca de 190 mil unidades escolares de ensino fundamental e médio em todo o Brasil (O GLOBO, 2014). O mau desempenho em 2009, no Ideb, colocou o Estado do Rio de Janeiro na penúltima posição entre os estados brasileiros, ficando à frente apenas do estado do Piauí. O ensino médio apresentava a situação mais grave, pois o índice geral fluminense, de 3,3 , caiu para 2,8 na rede pública estadual. 
Já em 2011, quando se iniciou a parceria entre a SEEDUC/RJ e a Fundação CECIERJ por meio do Programa de Formação Continuada de professores, descrito neste artigo, o ensino médio do Estado do Rio de Janeiro subiu oito posições no ranking nacional. Em 2012, o Ideb divulgado referente à rede estadual do Rio havia subido 11 posições, saindo da $26^{a}$ para a $15^{a}$ colocação no ensino médio, sendo o estado que alcançou o maior número de posições, ao lado do Estado de Goiás (SEEDUC, 2014).

De acordo com dados divulgados pelo Ministério da Educação (MEC), em setembro de 2013, o Rio de Janeiro saltou da $15^{a}$ posição (com 3,2) para a quarta (com 3,6), empatando com o Ideb dos estados de Santa Catarina, Minas Gerais e Pernambuco (O Globo, 2014). Com nota 3,6, as escolas estaduais do Rio superaram a meta de 3,3 estabelecida pelo MEC para 2013. Na região Sudeste, essa foi a segunda melhor nota, ficando atrás apenas de São Paulo. No Brasil, o Rio de Janeiro alcançou o segundo maior crescimento na nota $(12,5 \%)$, ficando apenas atrás de Pernambuco $(16,1 \%)$.

Outro índice importante da educação básica no Brasil é o Índice de Desenvolvimento Estadual (Ide), que mede a qualidade do aprendizado nos estados brasileiros. Os indicadores adotados para avaliar esse quesito foram o desempenho dos alunos nas séries iniciais do ensino médio na Prova Brasil (Português e Matemática) e o grau de distorção idade-série. De acordo com uma pesquisa realizada pelo Jornal Zero Hora (2014) e a Pontifícia Universidade Católica do Rio Grande do Sul (PUCRS), de acordo com o resultado do Índice de Desenvolvimento Estadual - RS (iRS) que compara o desempenho das escolas estaduais do Estado do Rio Grande do Sul com as escolas estaduais dos demais estados brasileiros, o Estado do Rio de Janeiro foi um dos que mais avançaram em Educação entre os anos de 2005 e 2012. A pesquisa, que também considerou outras duas dimensões (padrão de vida e longevidade), revelou que o Rio de Janeiro passou do $16^{\circ}$ para o $6^{\circ}$ lugar. Nesse período, houve uma melhora de $29,38 \%$ na Educação $(0,473$ para 0,612$)$.

Em relação à taxa de distorção idade-série, referente ao ensino médio, de 2007 a 2013 o estado obteve uma redução superior à média brasileira (21,4\% contra $13,6 \%)$, apresentando a $6^{a}$ maior queda nesta taxa. Esse resultado foi alcançado graças a um conjunto de ações estratégicas, como a adoção de um currículo mínimo para todas as escolas, implantação de avaliações bimestrais, oferta de reforço escolar 
para alunos com dificuldade de aprendizagem, formação continuada para professores de Língua Portuguesa e Matemática em escolas com baixo desempenho, além da introdução de metodologia de aceleração de estudos para os alunos com distorção idade/série.

Já com a nova versão da revista Educação Pública, pretende-se atingir o desenvolvimento de uma nova postura dentro da prática do magistério, valorizando as experiências do professor e deslocando-o da condição única de leitor para a condição de autor. Além disso, por meio da nova versão da revista pretende-se proporcionar a divulgação da pesquisa científica realizada por professores da rede estadual pública de ensino do Estado do Rio de Janeiro, em constante atualização teórica aliada ao desenvolvimento de novas e diversificadas habilidades que os torne mais aptos a lidar com as constantes mudanças e com a rápida evolução da sociedade.

Em 2015, estão previstas a realização de 20 oficinas, em diferentes regiões do Estado do Rio de Janeiro, para a capacitação de professores da rede estadual de ensino sobre o uso de tecnologias como recursos pedagógicos, principalmente os utilizados nos planos de trabalho publicados no repositório CRV. Também está prevista a realização de 20 encontros, em diferentes regiões do estado do Rio de Janeiro, para a difusão de experiências de sucessos dos professores da rede estadual e divulgação da nova versão da revista de Educação Pública da Fundação CECIERJ.

Durante a avaliação dos eventos e das oficinas previstos pretende-se medir, por meio de relatórios de acompanhamento, os resultados do uso do sítio CRV, das consultas realizadas pelos professores à nova versão eletrônica da revista de Educação Pública e de que forma esses recursos estão contribuindo para uma inovação tecnológica e metodológica em ambiente escolar da rede pública de ensino.

Até meados de 2015, pretende-se alcançar a seguinte meta de cadastramento no repositório CRV: 5.000 documentos, dentre planos de trabalho, orientações pedagógicas, roteiros de atividades (versão do professor conteudista e professor cursista) e 300 links para objetos de aprendizagem (vídeos, imagens, etc.) das diversas disciplinas do currículo mínimo. 


\section{Agradecimentos}

À Fundação Carlos Chagas Filho de Amparo à Pesquisa do Estado do Rio de Janeiro - FAPERJ pela liberação de fomento sob o número de processo E26/111.124/2013, por meio do Edital no 19/2013- "Programa Apoio à Instituição Estadual de Educação Superior a Distância e Divulgação Científica - CECIERJ/CEDERJ 2013".

\section{Referências}

Bastos, E.S.R. \& Fernandes, M.C.P. Centro de Referência Virtual: Compartilhando Experiências de Sucesso na Formação Continuada de Professores. Artigo aprovado para ser publicado nas atas do congresso ticEDUCA2014 - III Congresso Internacional TIC e Educação. Lisboa, Portugal, acesso em 16 de novembro de 2014, disponível em http://ticeduca2014.ie.ul.pt/index.php/pt/

Dutra, R.L.S \& Tarouco, L.M.R (2007). Recursos Educacionais Abertos (Open Educational Resources). Centro Interdisciplinar de Novas Tecnologias da Educação (CINTED). Universidade Federal do Rio Grande do Sul (UFRGS). V. 5 No 1, Julho 2007. Acesso em 14/10/2014, disponível em http://seer.ufrgs.br/index.php/renote/ article/view/14171/8099

Doll, W.E., Jr (1993). Currículo: uma perspectiva pós-moderna. Porto Alegre (RS): ArtMed Editora.

Fernandes, A. P. (2013). Perspectivas para o ensino coletivo de violão: em busca de uma abordagem holística. Dissertação de Mestrado em Educação Musical, Escola de Música, Universidade Federal do Rio de Janeiro, Rio de Janeiro, RJ, Brasil.

Imbernón, F.(2011). Formação Docente e Profissional (9a ed). São Paulo: Cortez Editora, pp. 50-51.

Kenski, V.M. (2011). Educação e Tecnologias - O novo Ritmo da Informação (8a ed). Campinas (SP): Papirus, p. 79.

Paquay, L. \& Perrenoud. P., Altet, M., Charlier, É. (Org.) (2001). Formando Professores Profissionais. Porto Alegre (RS): Artmed Editora.

Peters, O. (2003). Didática do ensino a distância. São Leopoldo (RS): Editora Unisinos. 
Peters, O. (2004). A Educação a Distância em Transição. São Leopoldo (RS): Editora Unisinos.

Pfeiffer, C. (2008). A Inclusão Social através da Educação Profissional na Modalidade a Distância Semipresencial. V Congresso Brasileiro de Ensino Superior a Distância (ESUD) e $6^{\circ}$ Seminário Nacional ABED de Educação a Distância (SENAED). Gramado (RS).

Pourtois, J.P. \& Desmet, H. (1999). A Educação Pós-Moderna. São Paulo: Edições Loyola.

Santos, A.I. (2006). Perspectivas Internacionais em Ensino e Aprendizagem On-Line. Santos (SP): Libra Três, p. 36, pp. 43-46.

Tardif, M.\& Raymond, D (2000). Saberes, tempo e aprendizagem do trabalho no magistério. Educ. Soc., Dez 2000, vol.21, no.73, pp. 209-244. ISSN 0101-7330.

Tardif, M.\&Gauthier, C. (2001). O Professor como "Ator Racional": que Racionalidade, que Saber, que Julgamento? In: PERRENOUD, P. et al. Formando Professores Profissionais: Quais Estratégias? Quais Competências? Porto Alegre (RS): Artmed, pp. 185-210.

Tardif, M. (2002). Saberes docentes e formação profissional (2a ed). Petrópolis (RJ): Editora Vozes, pp. 39-40. 